\title{
Beyond ABET: A new school-wide process for continuous improvement in engineering education
}

\author{
Professor Dick K.P. Yue and Barbara Masi, Ph.D. \\ Massachusetts Institute of Technology
}

\begin{abstract}
Having brought 13 programs successfully through ABET's challenging new EC2000 accreditation requirements, the most interesting outcome of that process was the identification of how much more could be done to create a streamlined, effective continuous improvement process for all. In the year following MIT's 2001 ABET review, the School of Engineering began implementation of a new school-wide continuous improvement process. The first step was the creation of a working team of departments and education specialists, the Engineering Council for Undergraduate Education (E-CUE). With broad jurisdiction over decision-making and resource allocation for education innovation projects in the School, E-CUE's mission is to act as a School-wide forum for sharing ideas and coordinating and facilitating the education innovation process across the School and collaborating units. One of the first action items of ECUE was to address the problem of the inefficient paper process for collecting subject and program level assessment and evaluation data. Drawing on faculty and department input, the new web-based system under development permits programs to easily access and track trends in senior, alumni, and freshman survey data and reports by learning outcome across years. In addition, the new system provides instructors with support tools that aid them in developing and assessing learning outcomes for each subject. The key role of E-CUE is to synthesize the wide range of assessment and evaluation data collected across the Institute, determine action, and allocate resources; the new web-based assessment system better enables E-CUE to carry out this role. An example of early action item was to address the weak connection between fundamental science and math subjects taken in the first year and practical engineering study; web-supported synthesis of many forms of data across departments including student performance and evaluation data, faculty evaluation and related reports enabled E-CUE to more rapidly identify problem areas, bring together a cross-department pilot team and develop solutions.
\end{abstract}

\section{Introduction}

Having brought 13 programs successfully through ABET's challenging new EC2000 accreditation requirements, the most interesting outcome of that process was the identification of how much more could be done to create a streamlined, effective continuous improvement process for all. There are four institutional levels for continuous education program improvement at many institutions: institution, school, department, and subject. As part of our post-ABET review, barriers to efficient continuous improvement at each level were identified. Barriers included lack of communication among the variety of committees at each level about education 
needs and improvements, paper reports and assessment data that were often difficult to track down, difficulty in tracking and comparing data collected across years, and difficulty in disseminating ideas on student learning assessment to busy faculty.

In order to create an efficient continuous improvement process at all levels, several changes were made in the organization of improvement efforts, storing of assessment and evaluation data, and support for program and subject assessment. First, the Engineering Council for Undergraduate Education (E-CUE) was formed as a School-wide group to identify shared problems, and work with institutional and department representatives toward solutions. Second, an engineering education website was created to support the work of E-CUE by creating a central repository for committee discussions, data analyses, reports and works in progress. The website was also designed to support departments and instructors by serving as a central source for program assessment data, as well as educational material and sample tools on program and subject assessment.

Creating a new organization entity to address institution, school or department education needs has been suggested by others. Rojas-Oviedo et al. suggested that each organization level should have a specific organization group that reviews assessment and evaluation data, recommends, and sometimes implements action ${ }^{5}$. Carter et al. has suggested best-practice processes for establishing program educational objectives and the importance of formal organization entities that collect and review appropriate constituent data ${ }^{2}$. Some have noted the value of websites for disseminating best-practice assessment tools ${ }^{2}$ or to track assessment data ${ }^{3,4}$. Educating engineering faculty on the variety of assessment tools available to measure student learning, and their appropriate use, has been an important activity since the issuing of the new EC 2000 accreditation requirements several years ago ${ }^{1,6}$.

\section{Background}

The MIT School of Engineering began its preparation for ABET accreditation review during 2000, a year and a half prior to its October 2001 ABET visit, by creating an ABET Committee. Made up of representatives from all departments, the group found that there were three key issues to be addressed in preparing for the visit. The first was how to formalize the somewhat informal education improvement processes taking place at the Institute, School, department, and subject levels. The second was how to clearly document the assessment and evaluation data collected as part of improvement processes at each level. The third was to acquaint School faculty and staff with appropriate assessment methods and commonly used education terminologies to ensure that all understood the new continuous-improvement-driven ABET requirements.

Over the course of the year, the group, with the assistance of education staff, moved from introductory seminars on program and subject assessment concepts and methods to tracking down and reviewing existing program and subject assessment and evaluation data. Once this process was complete, each program was guided in determining weak points in existing data and methods and supported in adopting strong program and subject evaluation plans. In some cases,

Proceedings of the 2003 American Society for Engineering Education Annual Conference \& Exposition

Copyright (c) 2003, American Society for Engineering Education 
new assessment or evaluation methods were adopted as supplements. The entire process of tracking existing data, seeking new data, and determining how that data could be used to improve programs and subjects was documented in each program's ABET Self-Study report. When the ABET Evaluation Team arrived in October 2001, faculty and staff from each program were more than ready.

After the ABET visit, the consensus across departments was that all that work should not wasted in an arduously created paper trail of continuous improvement. Many felt that the momentum created ABET preparation should be transformed into strong, efficient continuous improvement processes. The three issues that the ABET team addressed during the past year of preparation remained, however, as barriers to creating such processes. Improvement processes, in the form of disconnected Institute, School, and program committees still did not work together toward common goals. Reports created by one group rarely made it to the hands of another group. More importantly, there was no School-wide group to identify shared education problems and transform them into solutions. Standard assessment and evaluation data collected from surveys and subject evaluations, and related reports were still in paper form; none of the data was collected in a central repository for ease of access. In addition, without a central repository, it was difficult to track improvements over time. This was particularly a problem for programs that needed the data for program continuous improvement processes. Finally, while many had adopted new assessment methods, there was no formal support for others interested in doing so.

\section{Website For Engineering Education Research and Assessment}

To support efficient, informed, data-driven group work at the engineering school, department and subject levels, a website devoted to engineering education research and assessment was created. By creating an integrated site for use at all three institutional levels, it was envisioned that education improvement processes at the three levels could also be integrated. The primary purpose of the website was to create a focused repository of materials related to engineering education. Material included E-CUE meeting notes, discussions and studies in progress, School of Engineering education reports, links to related education activities, pertinent education publications, department assessment and evaluation data from 1994 to the present, and tools for program and subject assessment and evaluation (Figure 1). The site will be described as it is used at each institutional level for education improvement processes.

\section{School-Level Education Improvement Process: Engineering Council for Undergraduate Education}

The first action to maintain momentum after ABET review was to create a School-wide group to work together on shared education issues. Formed by Dean Tom Magnanti in Spring 2002, the mission of the newly formed Engineering Council for Undergraduate Education (E-CUE) is to:

- To identify, develop, disseminate, and implement best practices in curriculum, pedagogy, and assessment in engineering education.

Proceedings of the 2003 American Society for Engineering Education Annual Conference \& Exposition

Copyright (C) 2003, American Society for Engineering Education 


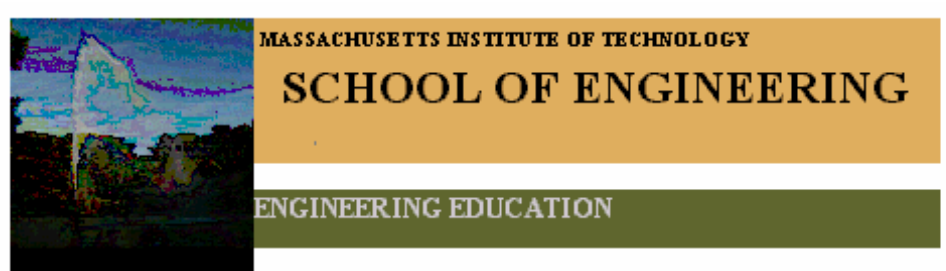

Welcome to our website for engineering education research and assessment.

E-CUE

ASSESSMENT

METHODS

This site contains:

DEPARTMENT

DATA

SPECIAL

REPORTS

READINGS

CONTACT

SCHOOL OF

ENGINEERING

- Engineering Council for Undergraduate Education (E-CUE) mission, meeting schedule, meeting minutes and current research projects.

- Assessment data for each School of Engineering department.

- Special research reports on undergraduate engineering education.

- Important readings in engineering education (curriculum development, assessment, engineering design, professional development).

For more information, please contact:

Barbara Masi, Ph.D.

Director of Education Assessment

School of Engineering

Room 1-206

$617-253-1860$

bamasiomit.edu

Figure 1. Introduction to engineering education website.

- To act as a forum for sharing ideas, and for coordinating, facilitating, fostering, and overseeing innovations and new curricula in engineering education across the School and with other units within and outside MIT.

Founded with the thematic focus of "Rethinking Undergraduate Engineering Education," E-CUE planned to:

- Support the development and implementation of innovative pedagogy and assessment methods and tools across the School. Develop more uniform and effective assessments of teaching and mentoring in the School.

- Reexamine the role of the School in the freshmen year as well as the integration of General Institute Requirements with the engineering curricula.

- Generate a comprehensive view of undergraduate engineering education in meeting broader educational objectives including engineering professionalism through curricula and "co-curriculum" programs and activities such as UROP and UPOP and departmental programs.

Proceedings of the 2003 American Society for Engineering Education Annual Conference \& Exposition Copyright (c) 2003, American Society for Engineering Education 
- Provide an effective platform for interactions and collaborations with other units within and outside MIT to achieve shared educational objectives.

Meeting monthly, E-CUE membership was organized to include representatives from across the Institute. E-CUE is chaired by the Associate Dean of Engineering, staffed by the School's Director of Education Assessment, includes a faculty representative from each of the School's departments and divisions, and a representative from the Office of the Dean for Undergraduate Education. Representatives from other Schools would be invited to send representatives for those projects that required cross-school action.

E-CUE hoped to break from the traditional process of previous School-wide education committees. Rather than relying on the informal input of members, or an incomplete sampling of pertinent data, E-CUE would be 'data-driven.' For each specific issue addressed by the group, existing data and reports would be reviewed and synthesized. Where data was lacking, supplemental, directed studies would be carried out. Once that process was completed, several strategies for action would be generated. Member discussions within the group, with experts and other Institute groups, would enable the group to determine the best solution from among potential strategies. To ensure that each step in the process was a productive one, each group member needed to remain informed of data under review and the discussion thread. Maintaining a website as discussions and ideas evolved would enable group members to make informed decisions.

The primary goal of the website would be to enable E-CUE to quickly find, review, and synthesize data for a given School-wide education issue. Another goal of the website was to enable E-CUE members to contribute to group work after meetings ended or even when they could not attend a meeting. All group materials would be available on the site for review. Members could review data in greater depth that was presented quickly during meeting times. A discussion group was embedded in the site to permit conversations to continue after the meeting.

An example of the use of the website for focused E-CUE work is shown in Figure 2. During academic year 2002-2003, E-CUE members, after review of institutional and department data, planned to focus the majority of its activity on 'Engineering and the Freshman Year.' Informal discussions with faculty revealed that the relationship between freshman year study of core math and science and upper level engineering study was no longer a strong one. As part of that project, E-CUE reviewed a number of existing reports on the freshman year, student ability data, and freshman survey data. The reports and report summaries were made available on the website for member review. Once reviewed, E-CUE members determined that additional data was needed to narrow down the specific problem to be addressed and explore possible solutions. Focused studies of engineering enrollment trends, learning outcomes in math and science core subjects, and freshman design were completed and reviewed. The new studies were also posted on the website. With all data available for public view, E-CUE was ready for informed discussions with engineering faculty, members of the School of Science as well as the Dean for Undergraduate Education. Those discussions led to a cooperative effort for improving the freshman year and its connection to engineering study.

Proceedings of the 2003 American Society for Engineering Education Annual Conference \& Exposition Copyright (C) 2003, American Society for Engineering Education 
By creating a comprehensive website that includes material for use at the School, department and subject level, E-CUE also has access to department assessment and evaluation data (Figure 3).

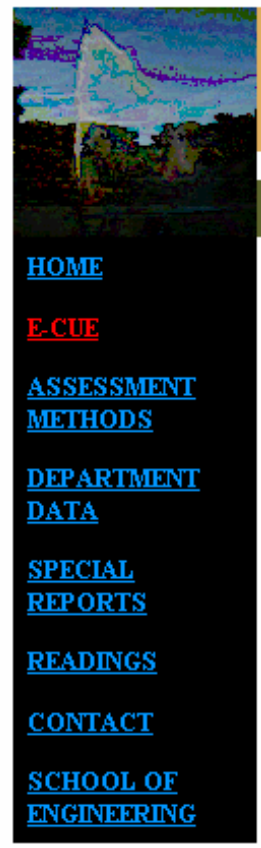

MASSACHUSE TTS INS TITUTE OF TECHNOLOGY

SCHOOL OF ENGINEERING

ENGINEFRTING AND THE FRESHMAN YEAR

E-CUE STRATEGY

- Possible E-CUE Strategies for the Freshman Year

- E-CUE Member Feedback

- E-CuE Proposal for the Freshman Year

REVIEW OF PAST FRESHMAN YEAR REPORTS AND

DATA

Summary of Reports and Data

- 1985 Humanities and Social Science Report

- 1989 Report of the Science-Engineering Working Group

- 1993 School of Engineering Education Committee Report

- 1997 Freshman Advising Comittee Report

- 1998 Task Force on Student Life and Leaming Report

- 1999 Educational Design Project Committee Report

- 1999 Student Sunver of the Freshman Year

E-CUE SPECIAL REPORTS OF THE FRESHMAN YEAR

- 2002 Engineering GIR Prerequisite Study

- 2002 Engineering Enrollment Study

- 2002 Engineering Design and the Freshman Year Study

Figure 2. E-CUE focus on Engineering and the First Year. 


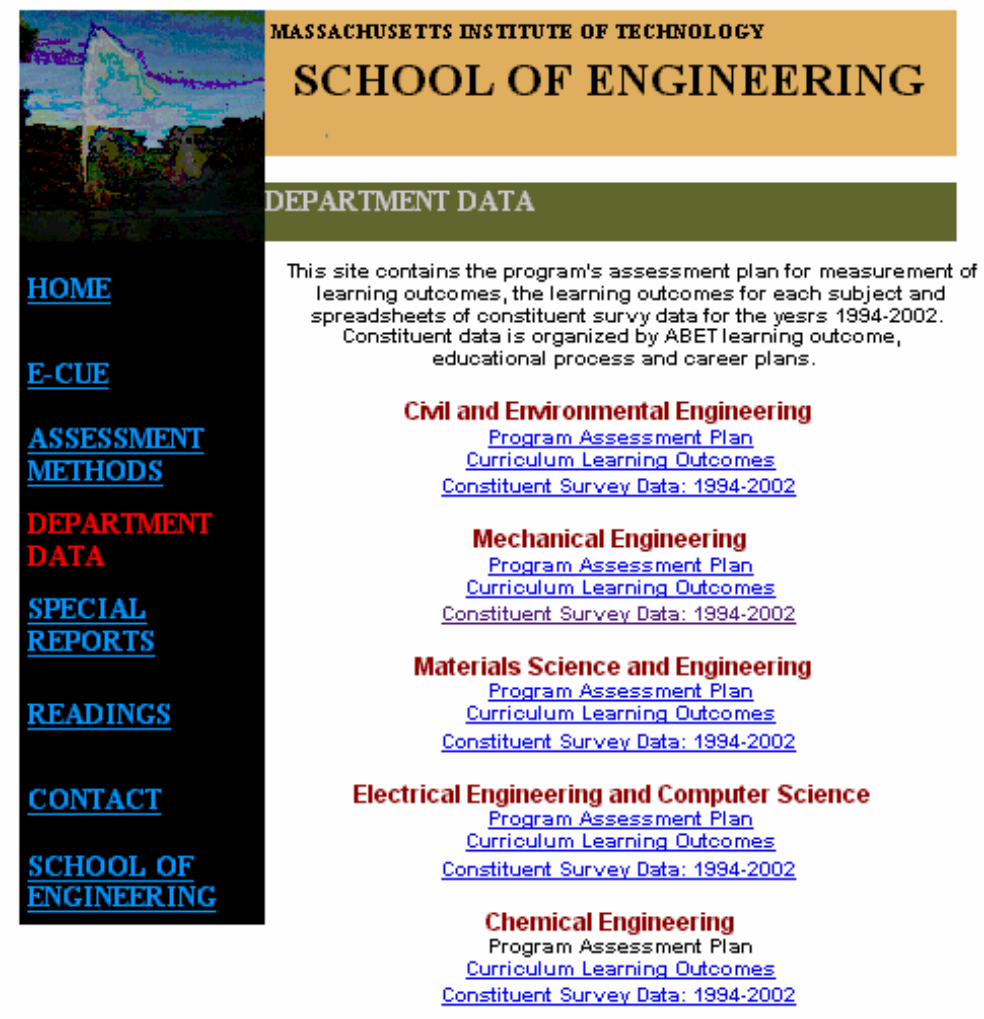

Figure 3. Department program assessment and evaluation data.

The data at this site includes senior, alumni and employer survey data from standard surveys distributed by the Institute and School of Engineering from 1994 to the present. Organized by program learning outcome, a rapid review of learning outcome data from across departments would enable E-CUE to quickly determine areas of common weakness. For example, data on math and science learning outcomes were accessed by E-CUE as part of its freshman year review. 
E-CUE can now work together with other Institute groups involved in education improvement and assessment. Another example involves E-CUE and efforts of an Institute assessment committee to improve the student survey used in subject evaluation. By posting the assessment committee's work-in-progress on the engineering education website, E-CUE members were able to provide input into the final survey product.

E-CUE focuses intensively on only one primary project per academic year. So that it can be prepared for emerging issues in ensuring years, other special engineering education reports are posted on the site as well in a section entitled 'Special Reports.' These can be reviewed as needed by E-CUE.

\section{Department-Level Education Improvement Process: Curriculum Committees}

Unlike School-level education improvement, all engineering departments had the traditional mechanism of the curriculum committee already in place. For most departments, the committee plays a strong, active role in periodic review of the undergraduate program curriculum. As ABET preparation revealed, most curriculum committees were hampered in their efforts by lack of or inappropriately presented data. Senior, alumni, or employer data was in paper form; years of data were never in a form for comparative review. Moreover, once each department had worked out a meticulous assessment and evaluation plan for review of educational objectives, the frustration with lack of timely data mounted.

It was envisioned that a website could support the work of the curriculum committee by providing a central repository for material required for formal program evaluation (Figure 3). The material included the program assessment plan (in matrix format) used for measuring each program learning outcome, the subjects in which each program learning outcome is addressed (in matrix format), and constituent data (standard program assessment and evaluation data collected from senior, alumni and employer surveys; graduate career tracking data). Assessment and evaluation data were embedded into an easily accessible EXCEL spreadsheet so that program officers could manipulate display the data as needed. A sample graphical output for constituent satisfaction with learning for several program learning outcomes is shown in Figure 4. By including material on which subjects address particular program learning outcomes, the curriculum committee can communicate with appropriate subject instructors if program level data show weakness in a given learning outcome. Collecting this material in one location also enables the curriculum committee to maintain a strong, balanced curriculum that achieves a high level of performance for all program learning outcomes. 


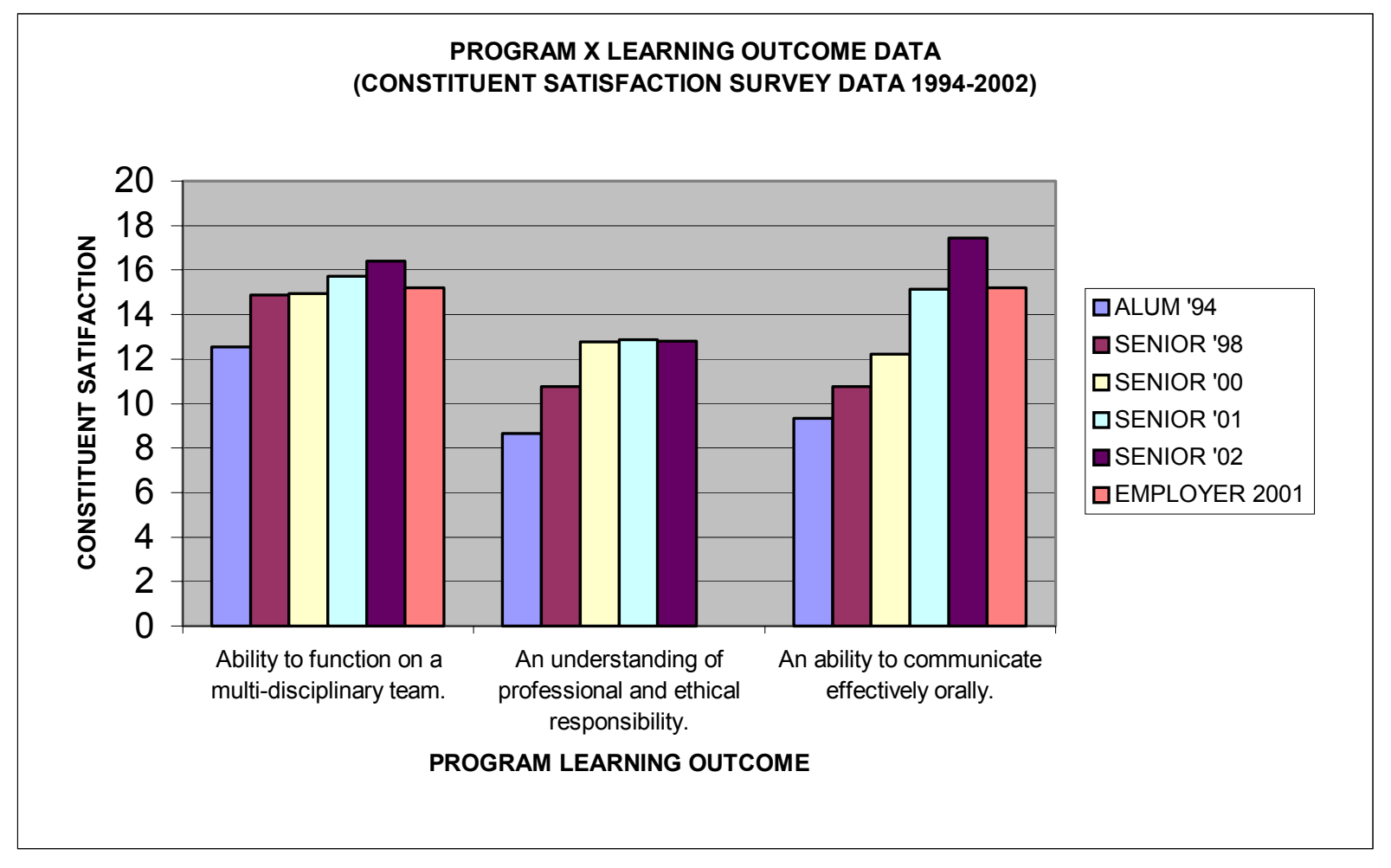

Figure 4. Sample program learning outcome data collected from constituent surveys.

Proceedings of the 2003 American Society for Engineering Education Annual Conference \& Exposition

Copyright (c) 2003, American Society for Engineering Education 


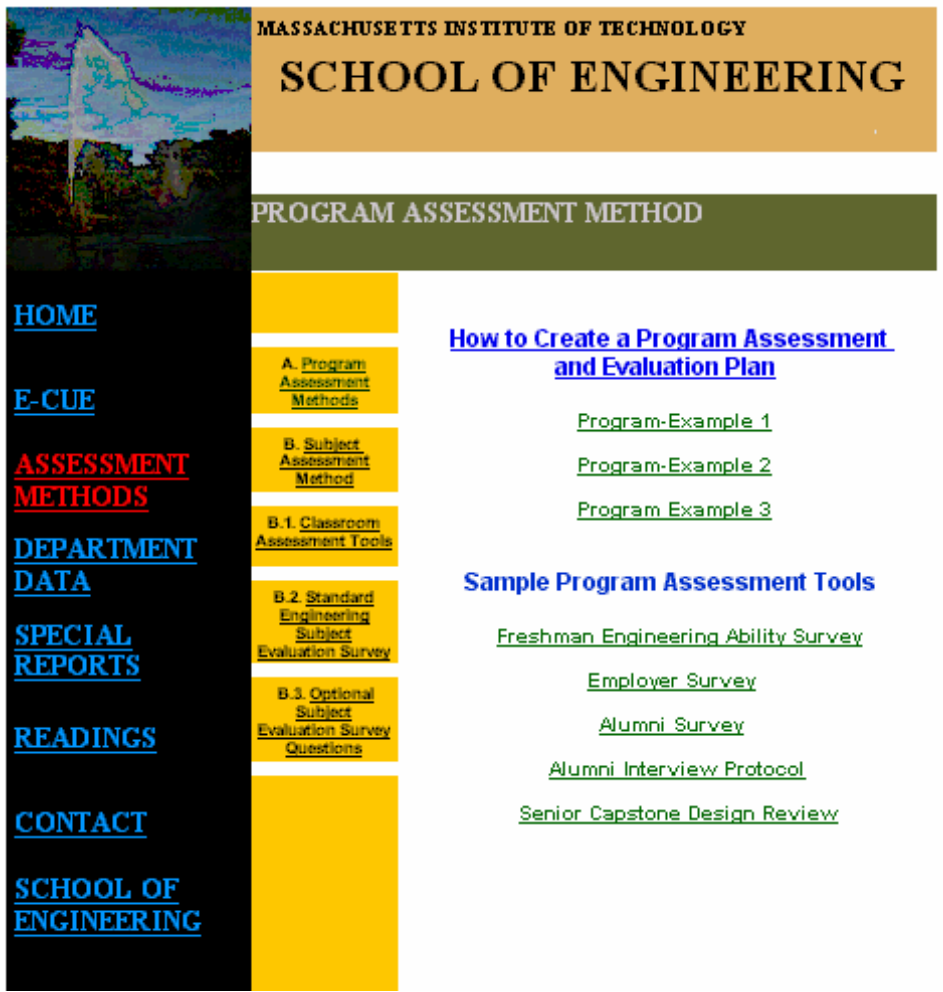

Figure 5. Program Evaluation Information and Tools

The website was also designed to educate curriculum committee and program officers on appropriate program assessment and evaluation methods for given educational objectives. Sample tools are available on the site for programs wishing to obtain supplemental data beyond the standard (Figure 5). In addition, the site contains a targeted set of engineering education readings on curriculum development, program evaluation, classroom assessment, engineering design education, and professional ability development.

\section{Subject-Level Education Improvement Process: Curriculum Committee and Subject Instructor Review}

Instructors work at the subject-level in continuous improvement of each undergraduate subject. As part of ABET preparation, instructors attended seminars on how to connect subject and program learning outcomes as well as how to measure student learning. It was difficult, however, for busy faculty to attend the seminars let alone develop new assessment tools. To address this barrier to subject-level improvement, a website was developed to introduce instructors to appropriate subject assessment methods (Figure 6). Sample subject assessment plans and tools were included that can be easily adopted or downloaded for classroom use. 


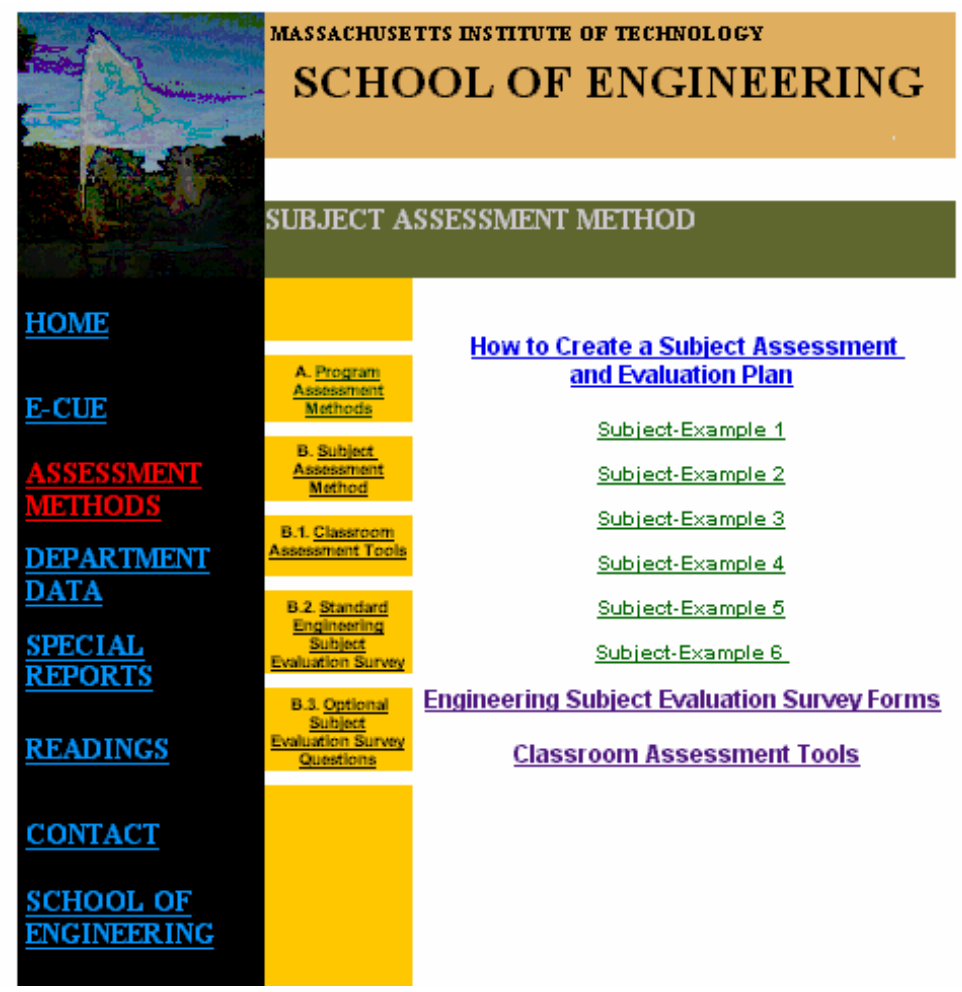

Figure 6. Subiect Assessment and Evaluation Tools

The newly designed standard engineering subject evaluation survey contains 10 open questions that instructors can use at their discretion. To assist instructors in quickly developing appropriate questions for a lecture, lab, or design subject, optional questions were also included in the website. In the long term, it is planned for instructors to be able to choose optional questions online and download a tailored subject evaluation survey for use in their subject.

\section{Conclusions}

The development of integrated education improvement processes and website have already led to unexpected benefits. Groups who rarely worked together, such as School of Science faculty who teach core math and science subjects and engineering faculty, are not being brought together to integrate engineering study with the freshman year. Discussions for development of new freshman subjects are grounded in a strong base of data that is easily shared. Departments are using standard assessment data from constituent surveys to motivate informed curriculum review and change. 
The work of 'improving' continuous improvement processes is far from complete. Plans to further support such processes include expanding available program evaluation and assessment tools and integrating collected subject evaluation data into the website.

\section{Bibliography}

1. Besterfield-Sacre, M., L.J. Shuman, H. Wolfe, C.J. Atman, J. McGourty, R.L. Miller, B.M. Olds, and G. Rogers, "Defining the Outcomes: A Framework for EC 2000," IEEE Transactions on Engineering Education, Special Assessment Issue, 43(2), 2000.

2. Carter, M., R. Brent, and S. Rajala, "EC2000 Criterion 2: A Procedure for Creating, Assessing, and Documenting Program Educational Objectives," Proceedings of the 2001 American Society for Engineering Education Annual Conference and Exposition, Albuquerque, NM, June 24-27, 2001.

3. Chow, T., Presentation on Rose-Hulman Web-based Portfolio Assessment System, Best Assessment Processes III Symposium, April 2-3, 2000, Rose-Hulman Institute of Technology, Terre Haute, IN, RosE Portfolio Demonstration website, http://www.rose-hulman.edu/irpa/old/REPS/index.html

4. McCurdy, L.B., D. Walcerz, W.Drake, “A Web-Based Approach for Outcomes Assessment," Proceedings of the 2001 American Society for Engineering Education Annual Conference and Exposition, Albuquerque, NM, June 24-27, 2001.

5. Rojas-Oviedo, R., Z.T. Deng, A. Jalloh, and A. Mobasher, "Engineering Education and the Continuous Improvement Process," Proceedings of the 2000 American Society for Engineering Education Annual Conference and Exposition, St. Louis, MO, June 18-21, 2000.

6. Shuman, L., M. Besterfield-Sacre, H. Wolfe, C.J. Atman, J. McGourty, R.L. Miller, B.M. Olds, G. Rogers, "Matching Assessment Methods to Outcomes: Definitions and Research Questions," Proceedings of the 2000 American Society for Engineering Education Annual Conference and Exposition, St. Louis, MO, June $18-21,2000$.

\section{DICK K.P. YUE}

Professor Dick K. P. Yue is the Associate Dean for Engineering at MIT. He is also a professor in the Department of Ocean Engineering. Professor Yue has initiated a number of engineering education innovation efforts in the School of Engineering including undergraduate internship programs in professional practice and entrepreneurship, online professional engineering education, and the Engineering Council for Undergraduate Education.

\section{BARBARA A. MASI}

Dr. Barbara Masi is the Director of Education Assessment in the MIT School of Engineering. She received her B.S. and M.S. in Materials Science and Engineering from MIT. She received a joint Ph.D. from the MIT Sloan School of Management and the Program in Science, Technology, and Society. Dr. Masi was an evaluator for the NSF ECSEL project and has consulted on numerous engineering education, online learning, and K-12 math/ science projects.

Proceedings of the 2003 American Society for Engineering Education Annual Conference \& Exposition Copyright (C) 2003, American Society for Engineering Education 